\title{
La violencia simbólica de la explotación sexual de mujeres en una celebración estudiantil
}

\author{
Rafael Gutiérrez,' Leticia Vega'
}

Artículo original

\section{SUMMARY}

The article analyzes a wild students' party that is part of a twentyfive-year old tradition of helping to finance students' graduation and other activities, in which young men and women participate in a theatrical re-enactment of sexual exploitation. The aim is to describe how symbolic violence can reproduce sexual exploitation in an emotionally gratifying way and how this transmutation is experienced by victims. The information reported is based on field work conducted in a student community at a higher education school in the conurbated area of Mexico City. Observations of the preparation, implementation and wild post-celebration were carried out in this community. In this context, several students between the ages of 17 and 23, including five women, participated in a focus group (two sessions) and in-depth interviews (three sessions) to describe the most significant dimensions of the celebration. The five students were invited to participate through an explanatory letter requesting their voluntary consent. A content analysis of the observation records and a literal transcription of the focus groups and interviews were conducted. The results indicate that the celebration, which includes a theatrical representation of sexual exploitation, includes some real components: concealment, abduction, auction, erotic dancing and sexual harassment. These elements are experienced with displeasure but relived by the informants and other participants as an exciting, rewarding moment. These results are explained by Bourdieu's theory of symbolic violence. We conclude that the celebration is a gratifying affirmation of the sexist beliefs and practices that legitimize the sexual exploitation of women and tacit acceptance of their abuse, which are often concealed, but recognized as a venerable tradition.

Key words: Symbolic violence, sexual exploitation, youth society.

\section{RESUMEN}

Se analiza una celebración estudiantil "desmadrosa" que es parte de una tradición desde hace un cuarto de siglo, que ayuda a financiar la titulación y otras actividades de los estudiantes y en la que las y los jóvenes participan en una representación histriónica de la explotación sexual. Los objetivos son describir cómo la violencia simbólica puede revivir de manera emotiva y gratificante a la explotación sexual y cómo esta transmutación es experimentada por las víctimas. La información reportada se basa en el trabajo de campo desarrollado en una comunidad estudiantil de una Escuela de Educación Superior de la zona conurbada del Valle de México. En esta comunidad se realizaron observaciones de la preparación, realización y post celebración "desmadrosa". En este contexto se conoció a varios estudiantes entre los 17 y 23 años, de ellos cinco mujeres, que participaron en un grupo focal (de dos sesiones) y en entrevistas en profundidad (de tres sesiones) para dar cuenta de las dimensiones más significativas de la celebración. Las cinco estudiantes fueron invitadas a participar mediante una carta explicativa, solicitándoles su consentimiento voluntario. Se realizó un análisis de contenido de los registros de observación y de la transcripción literal de los grupos focales y de las entrevistas. Los resultados indican que la celebración, que tiene una representación histriónica de la explotación sexual, incluye algunos componentes reales: ocultamiento, rapto, subasta, baile erótico y acoso sexual. Estos elementos son experimentados con disgusto por las informantes pero son revividos por los demás participantes como un momento emotivo y gratificante. Estos resultados son explicados conforme a la teoría de Bourdieu acerca de la violencia simbólica. Se concluye que la celebración es una afirmación complaciente de las creencias y prácticas machistas que legitiman la explotación sexual de las mujeres y una aceptación tácita de sus abusos, los cuales, aunque suelen ser ocultados, sí son reconocidos como una tradición venerable.

Palabras clave: Violencia simbólica, explotación sexual, socialidad juvenil.

chadas, transportadas, transferidas, retenidas, entregadas, recibidas o alojadas con fines de explotación sexual por criminales en los bares, las casas de citas, los hoteles, las zonas de tolerancia, o por medio de la pornografía infantil y el turismo sexual, entre otros negocios de la industria del sexo. En cualquier caso, los proxenetas someten a las vícti-

Dirección de Investigaciones Epidemiológicas y Psicosociales. Instituto Nacional de Psiquiatría Ramón de la Fuente Muñiz.

Correspondencia: Mtra. Leticia Vega. Dirección de Investigaciones Epidemiológicas y Psicosociales. INPRFM. Calz. México-Xochimilco 101, San Lorenzo Huipulco, Tlalpan, 14370 México, D.F. Tel: 4160 -5149. E-mail: vegahl@imp.edu.mx 
mas para que permanezcan en la industria sexual mediante los engaños, la privación de la libertad, las amenazas, las palizas, la alcoholización o la imposición del consumo de otras sustancias adictivas, etc. ${ }^{1-3}$

Hasta la fecha, los datos sobre la salud y la trata de personas son limitados a nivel mundial. Una reseña de 2012 identifica 16 estudios, casi todos ellos centrados en la violencia y los problemas de salud sufridos por mujeres y niñas víctimas de trata con fines de explotación sexual; ${ }^{4}$ los datos se centran en general en la salud sexual (especialmente en relación con la infección por el VIH) y, en menor grado, se refieren a problemas de salud mental, ${ }^{5,6}$ tales como la depresión, las adicciones, la baja autoestima, los trastornos de ansiedad, la agorafobia, el trastorno obsesivo compulsivo, los trastornos de conducta alimentaria, entre otros.

Los resultados también indican que la trata de personas con fines de explotación sexual se concreta en los escenarios de la industria del sexo, pero también puede culminar en otros contextos comunitarios. ${ }^{7}$ Por ejemplo, en algunos hogares es posible encontrar a niñas y niños transferidos o entregados por su madre o padre a su acreedor, quien los recibe y aloja con el fin de abusar sexualmente de ellos a cambio de olvidar las deudas de los progenitores, por ejemplo las rentas de la vivienda familiar. Otro caso es el de mujeres jóvenes o adolescentes raptadas en su comunidad y retenidas por la fuerza en el alojamiento de sus raptores con el fin de abusarlas sexualmente por tiempo indefinido (días, semanas o meses); casi siempre hasta que las víctimas son asesinadas, escapan o son liberadas por la policía, los vecinos o el propio abusador.

En la trata con fines de explotación sexual es casi total la libertad de los explotadores, regularmente hombres, para tratar de modo cruel e inhumano a sus víctimas (mujeres y personas menores de edad), avasallando sus derechos humanos a la dignidad, la libertad y la igualdad. En el proceso de la trata con fines de explotación sexual intervienen varios tipos de explotadores: los proxenetas, los pornógrafos, los clientes de la industria sexual, los turistas sexuales, los pederastas, entre otros. En las relaciones de explotación hay un elemento de terror personal, que varía de explotador a explotador, y que puede tomar la forma de tundas despóticas, toda clase de abusos sexuales, además de otros insultos y humillaciones.

Todo esto se considera violencia de género en su forma de trata de personas con fines de explotación sexual, la cual tiene por lo menos tres facetas: la violencia directa (las golpizas, las violaciones, las amenazas, etc.), la violencia estructural (la captación, el enganchamiento, el traslado, la retención, etc.) y la violencia cultural (la tolerancia, la normalización y la legitimación de las violencias directa y estructural). Las principales características de la violencia estructural y directa de la trata de personas con fines de explotación sexual han sido documentadas por diferentes investigaciones. ${ }^{1-6}$ Sin embargo, la violencia cultural ha sido poco caracteriza- da en tanto violencia simbólica, ${ }^{8}$ es decir, como todas aquellas prácticas de invisibilización y de naturalización de las violencias directa y estructural de la trata. La violencia simbólica, ${ }^{8}$ legitima ambas violencias mediante dos operaciones simultáneas: una, las oculta (la verdad "objetiva"), mientras que la otra construye la "verdad subjetiva", logrando que las violencias estructural y directa sean percibidas como atributos naturales, normales. Así es posible que la violencia simbólica de la trata transfigure las violencias de forma tal que la clientela de la industria sexual, mayoritariamente masculina, pueda ver una conducta humillante de la víctima como una expresión de amor, el abuso sexual como una entrega pasional o la explotación sexual como un negocio lucrativo de ellas.

Con los objetivos de describir cómo la violencia simbólica puede revivir de manera emotiva y gratificante a la explotación sexual y cómo esta transmutación es experimentada por las víctimas, se reporta una investigación de una celebración estudiantil "desmadrosa". * En ésta se organiza una especie de representación histriónica de la trata con fines de explotación sexual a cargo de las y los estudiantes, en la que se dramatiza la captación, el enganchamiento, el transporte, la transferencia y la subasta de estudiantes con el fin de hacer una exhibición pública de orden sexual, un baile erótico que será remunerado por terceros.

Este tipo de celebración es parte de la socialidad juvenil. Esta noción es una propuesta de Maffesoli, ${ }^{9}$ para sintetizar el concepto de "sociabilidad" de Simmel, ${ }^{10}$ que enfatiza el gusto y el aspecto lúdico de la unión con otros y la concepción nietzscheana de los excesos del goce dionisiaco y del predominio de la estética sobre la ética. De este modo, Maffesoli, ${ }^{9}$ caracteriza a la socialidad como una manera tribal de compartir la emoción, el juego, la aventura y el placer dionisiaco.

Los estudios realizados en México, ${ }^{12,13}$ reportan que de manera paralela a la socialidad juvenil ocurre un proceso de subjetivación que abstrae a los jóvenes del desmadre impidiéndoles reflexionar críticamente sobre su "sí mismo", su conducta y sus responsabilidades; sin embargo también hay reportes de que esa "abstracción reflexiva" parece reducirse en los contextos de socialidad donde predomina la embriaguez alcóholi$\mathrm{ca}^{12}$ y la agresión sexual colectiva contra las mujeres. ${ }^{15}$

\section{MÉTODO}

La investigación se realizó en una comunidad estudiantil de una Escuela de Educación Superior (EES) ubicada en la zona

\footnotetext{
* En México, la palabra desmadre es polisémica, su sentido depende del contexto en el que se emplee. Literalmente significa "sin madre", pero se usa comúnmente para referirse al caos, la indisciplina y la falta de moral. También la expresión se ocupa para referirse a un enredo divertido. Incluso, muchas veces se ocupa para referirse a una acción colectiva que al mismo tiempo que es indisciplinada o violenta, resulta lúdica para sus autores. Este último sentido adquiere la expresión desmadrosa, usada aquí para calificar a la celebración estudiantil.
} 
conurbada del Valle de México (ZCVM), donde varios municipios del Estado de México hacen contacto con distintas Delegaciones del Distrito Federal. Se trata de una de las zonas más pobladas e inseguras del país. En la primera década del siglo XXI, la zona llegó a sumar más de 22 millones de habitantes y aparecía en los primeros lugares de infanticidios, feminicidios y robos a nivel nacional. ${ }^{7}$

\section{Participantes}

En el contexto de la EES se conoció a varios hombres y mujeres estudiantes entre los 17 y 23 años de edad, pero sólo cinco mujeres participaron en un grupo focal (de dos sesiones) y tres de ellas en entrevistas en profundidad (de tres sesiones) para dar cuenta de las dimensiones más significativas de la celebración. Dos de ellas tenían entre 22 y 23 años de edad y conocían a detalle el fenómeno, las otras tres estudiantes (de 17,18 y 19 años de edad) habían participado como "esclavas" en la celebración. Las cinco estudiantes fueron invitadas a participar mediante una carta explicativa, solicitándoles su consentimiento voluntario.

\section{Instrumentos}

En esta investigación cualitativa se utilizó la observación, la entrevista en profundidad y la técnica de grupo focal. Se realizaron observaciones de la preparación del festejo, su realización y post celebración. Además se consultaron las redes sociales "you tube" y "facebook" del comité estudiantil organizador, de los años 2011 a 2012. Las observaciones quedaron registradas en un diario de campo, en el que se incluían fotos, comentarios estudiantiles relativos a la celebración y las interpretaciones de los investigadores.

\section{Procedimiento}

Primero se conformó un grupo focal de dos sesiones de 50 minutos cada uno con las cinco informantes, llegando a la saturación de datos. Después de analizar las dos sesiones del grupo focal, se identificaron a tres informantes clave para ser invitadas a participar en una entrevista individual sobre las dimensiones del fenómeno que mejor conocían. Con cada una de las seleccionadas se realizaron tres sesiones de entrevista de 50 minutos por ocasión. Para la conducción de los grupos focales y entrevistas se diseñaron distintas guías de preguntas. Las técnicas de registro, previa autorización de las participantes, fueron grabaciones digitales y notas de campo.

A partir de los registros de observación y de la transcripción literal de la información obtenida en los grupos focales y en las entrevistas, se realizó un análisis de contenido de la información obtenida con cada técnica, en el cual se identificaron las citas textuales y se organizaron en categorías y en familias de categorías.

\section{RESULTADOS}

Los principales resultados fueron agrupados en el siguiente orden: la organización, la celebración, la socialidad y la explotación sexual de las esclavas.

\section{La organización}

Desde hace 25 años el Comité de Estudiantes de la Escuela Superior organiza una celebración desmadrosa para conmemorar las largas caminatas que hacían las primeras generaciones de estudiantes para llegar a la escuela, en una época donde no había transporte público directo ni lugares para tomar algún refrigerio en los alrededores. Esta situación es recordada con una celebración desmadrosa y un baile. El primero se desarrolla durante el día, el otro por la noche. El Comité organiza estos eventos porque los considera parte de las tradiciones estudiantiles y para financiar la titulación y otras actividades de los estudiantes.

La celebración se realiza un par de semanas antes de finalizar el año, pero su organización comienza desde los primeros meses. Desde entonces el Comité da a conocer sus planes de trabajo a las autoridades escolares, donde les anticipa la organización y las fechas de la celebración y el baile. Con ello el Comité busca el permiso de las autoridades para ocupar las instalaciones donde se puedan desarrollar algunos eventos, como la lucha libre, la venta de "esclavas/os" y el baile.

Otra de las actividades del Comité consiste en negociar con las autoridades de la Delegación política y del sistema de transporte colectivo, el permiso y apoyo para desplazarse con seguridad por las calles (vigilancia policiaca y ambulancia médica) y facilitar su acceso y traslado por el transporte colectivo. El Comité también se dedica a conseguir locutores de radio, $D J s$ y grupos de música en vivo para amenizar la celebración, los alimentos y bebidas que se consumirán así como organizar la venta de boletos para el baile y toda la logística de protección de las instalaciones escolares y de seguridad para los participantes.

Además el Comité promueve la celebración entre la comunidad estudiantil, la cual se multiplica gradualmente conforme se acerca el evento. Representantes del Comité visitan los salones para motivar la participación de los estudiantes. No es fácil esta labor de convencimiento. Al respecto, una joven comenta: "al principio todo el salón estaba renuente, decíamos ¿por qué vamos a correr?, ¿por qué tenemos que disfrazarnos y andar en la calle? ¡Se van a burlar de nosotros! Los del Comité te explican, te dicen: 'todos lo hacemos y es una tradición'".

\section{La celebración}

La convocatoria logra conjuntar a cientos de estudiantes el día de la celebración. Quienes más participan son los jóvenes de primero y segundo grado y en menor medida los de 
tercero, mientras que los de cuarto lo hacen todavía menos, (están por terminar sus estudios). De esta manera se pueden observar grupos de estudiantes disfrazados de narcos, luchadores enmascarados, mujeres ataviadas de súper héroes, de conejitas de play boy y de militares. También hay estudiantes con botargas y otros más sin disfraz. Conforme llegan los grupos de estudiantes a la escuela, se ordenan detrás de un camión ocupado por los miembros del Comité, la mayoría hombres.

El camión del Comité encabeza la caminata desmadrosa, le da ritmo: se adelanta, se detiene, camina lentamente, acelera; mientras sus seguidores la siguen, echan porras, chiflan, cantan, corren, caminan, se atropellan, etc. Durante el desplazamiento destacan algunos eventos, como:

- $\quad$ El recordatorio del origen de la celebración y agradecimiento a un restaurante donde les regalan alimentos a los estudiantes para agradecer su preferencia.

- La lucha libre en lodo, donde participan mujeres en albercas inflables llenas de agua lodosa. Este evento ocurre mientras los estudiantes esperan el regalo de alimentos.

- La carrera de alimentos: a distintos equipos de estudiantes se les da un gran plato de comida que tienen que cargar en conjunto. El reto es regresar corriendo con los alimentos a la escuela, llegar en primer lugar y con la comida mejor conservada.

- La explotación sexual de las "esclavas". Durante la celebración, se reclutan "esclavas" y "esclavos", son retenidos y trasladados a la escuela. Después son subastados al mejor postor, quedando obligados a bailar para el comprador.

La celebración desmadrosa es un momento festivo, exclusivo de una comunidad estudiantil de la ZCVM, lo cual presupone la participación de cuerpos jóvenes, vigorosos y sanos, que pueden correr o tirarse desde el toldo de un camión, sin límites físicos, como el cansancio o cualquiera otra limitación.

En esta celebración se transgrede el orden y los roles sociales existentes. Las jerarquías pueden resultar reforzadas o invertidas. Se trata de un ritual que rompe las rutinas escolares y de la cotidianeidad de sus alrededores. Específicamente la celebración es un ritual de inversión, pues desplaza de su contexto cotidiano a elementos y sentidos disímiles (por ejemplo los disfraces de superhéroes y la representación de la esclavitud). De hecho el desplazamiento es en sí un invertido, pues el objeto no es arribar a algún lugar específico, sino el marchar mismo. Lo importante de estos desplazamientos es que unen los elementos disímiles en un acto, generando así una experiencia de unidad, de cohesión juvenil.

\section{La socialidad}

Además, la socialidad juvenil es un conjunto de rituales compartidos por los estudiantes $\mathrm{y}$, en ese compartir, los sujetos se relacionan con determinado sentido frente a los otros. Por medio de los ritos la comunidad de jóvenes estudiantes se reconoce a sí misma, reafirmando sus significaciones imaginarias sociales. Por ejemplo, participar en la celebración parece, desde los relatos de las mujeres participantes, un momento extraordinario, de identificación emocionante con la institución y comunidad escolar. Por ejemplo, Brenda, una estudiante participante de la celebración relata:

Hasta los (estudiantes) que no venían vestidos y no se sentían parte del grupo o de la escuela, ya en el momento de estar allá (en la celebración), echaban las porras. Se dice el alma mater que es como un himno que hacen en la institución, y ese no me lo sé pero allá te lo leen, después de eso te dicen: juna porra!, jen esta chiflan! y nada más gritan: ¡EEEEEEESEEEE! y vuelven a chiflar. Gritan ¡EEEEEEEESEEE! y vuelven a chiflar y al final dicen; iduro! Esa parte de los chiflidos es muy emotiva porque todos aunque no sepamos chiflar hacemos como si supiéramos. Esto es como un himno que tiene la institución. En el momento de estar en la celebración te sientes parte del grupo, bueno de toda la institución, porque es ponerte la playera y decir soy de la escuela, aunque no seas tan relajiento o sea te envuelves, es como cuando estás en el estadio y están echando la porra, participas del mismo entusiasmo que sientes, entonces yo sentí esa emoción y como que alegría ¿no?

La celebración logra la conformación de una identidad colectiva, una plena identificación con el grupo de estudiantes y con la institución escolar. Desde los relatos de las mujeres se puede apreciar que su identificación con el grupo resulta fascinante y emotiva.

En la exaltación del júbilo colectivo, las mujeres y los hombres jóvenes quedan expuestos al movimiento autodestructivo del desmadre, lo cual es muy arriesgado, como Brenda lo dice:

Iba corriendo durante la celebración y ya después me subí al camión, de hecho me avente de él. Luego se me ocurre aventarme con la mano hacia arriba como superhéroe y el camión iba en movimiento, fue muy arriesgado lo que hice porque no me cacharon y me lastimé una rodilla. A todos los agarraban, antes se había aventado el chocorrol y otra botarga, pero no se qué pasó conmigo. Sí me agarraron pero ya que mi rodilla estaba en el suelo.

Este primer acercamiento a la escena pública de la celebración como una manera tribal de compartir la emoción, el gusto y el aspecto lúdico de "vibrar juntos"12 en el juego, la aventura y los excesos del goce dionisiaco, también puede leerse como una afirmación complaciente de las creencias y prácticas machistas que legitiman la explotación sexual y una aceptación tácita de sus abusos, los cuales no son reconocidos como tales sino como una tradición venerable.

\section{La explotación sexual de las "esclavas"}

Las dramatizaciones son un elemento clave de la celebración. En éstas las desigualdades de género son transmutadas en una tradición fascinante y emotiva, incluso en un juego. Los abusos de poder y el rol de mercancía sexual de las mujeres resultan evidentes en la dramatización de la ex- 
plotación sexual de las esclavas. Ésta transcurre en varias escenas: el reclutamiento, el transporte y la entrega; la exhibición, la subasta y el baile erótico.

\section{El reclutamiento}

Aunque se busca esclavizar tanto a hombres como a mujeres, en la práctica predominan las jóvenes esclavizadas. Las informantes dicen que porque no hay hombres guapos, además argumentan que lo tradicional es que los hombres compren esclavas y que las mujeres bailen sexy.

De acuerdo con algunas informantes, eligen a las mujeres de primer ingreso por su ingenuidad y novatez. Una informante declara: "Dicen los del Comité: ves a varias de las de primero, agárrate a esas porque no saben bien como está el movimiento". Otra informante ex esclava dice: "De hecho agarran a muchas de primero, es raro ver a otras de otros años, se agarran a las que no saben".

Antes de la celebración, algunas estudiantes ingenuas son elegidas y enganchadas para ser esclavas, por ejemplo Rocío:

Desde antes me eligieron para ser esclava en la celebración, porque era amiga de uno de los del Comité, ese día iba de la mujer maravilla y me dijo que iría en el camión con las otras chicas elegidas. Que era para sacar más dinero para los que se graduaban, y te daban un boleto para ti y para tu acompañante para el baile, que era una tradición, me dijo que pues se elegían a las más guapas, en ese momento me sentí halagada, es que te consideran entre las guapas.

El reclutamiento también puede ocurrir a través de grupos de amigos, quienes se confabulan para captar esclavas entre algunas de las amigas que siguen al camión. Las persiguen, las alcanzan y las suben al camión, Berenice comenta:

Yo tenía unos amigos del Comité, me corretearon y me agarraron, fue muy gracioso, porque me dijeron vas a ser esclava para la celebración, ven súbete al camión, pues yo estaba toda desprevenida y como eran varios pues me tuve que subir, jajaja... bueno ya sabes el camión en donde llevan a todas las chicas que son esclavas. Mis amigos uno que se llama Chucho fue el que me dijo primero, pero en realidad el elegirme como esclava fue idea de mis amigos. Pues... la verdad me daba mucha pena, y me subieron al camión y entonces yo no quería. Te digo que fue así de repente, y como son mis amigos les hice caso. La verdad fue tan rápido que no me imaginaba, ni tenía planeado ser esclava, así que no tenía así como una visión de lo que esperaba.

\section{El transporte}

El camión transporta a las esclavas captadas durante toda la celebración, desde afuera el vehículo luce repleto de jóvenes hasta el toldo. Dentro del camión todos van apretujados: algunos son miembros del comité, otros son estudiantes captores, esclavas y algunos esclavos. Arriba del toldo van algunos estudiantes, botargas y esclavas animando la marcha. En medio del júbilo colectivo, botargas y esclavas se tiran uno a uno del toldo del camión, esperando que los cachen los estudiantes que los siguen a pie y les esperan abajo. Mientras los que están dentro del vehículo cantan, gritan, echan porras, brincan con entusiasmo. En ese camión van Rocío y Berenice, ambas desconocen lo que implica ser esclava. Berenice supo que tenía que subir al camión. Nunca le dijeron lo que tendría que hacer como esclava. En el caso de Rocío, la halagaron al informarle que por guapa ella sería esclava y que con eso ayudaría a la graduación de los estudiantes. Que ganaría boletos para el baile, que era una tradición.

Terminada la trayectoria del camión, las esclavas y esclavos son entregados a los miembros del comité, quienes les informan lo que implica ser esclava o esclavo. Al respecto Rocío comenta:

Al inicio de ser esclava estaba muy contenta, halagada pero pues después si ya me dio miedito, cuando te dicen que tienes que bailarle primero a unos y luego a quien te compra. Sólo te dicen eso de que te subastan para que según quien te compre esté contigo en el baile y de que es para reunir dinero, pero no te dicen que tienes que bailar así sexy. Sexy es como mover mucho las caderas, las pompas, hacerlo provocativo, como estilo "reggaetón" no me agradó porque no suelo bailar así en medio de la escuela, y no eso como que ya no me agradó además eso es más personal y si te nace. No me gustó que no me dijeran desde el principio cómo iba a estar todo, la verdad sí te sorprende.

Rocío se sorprende porque se trata de una realidad hasta ese momento ocultada por el Comité, y que podemos reconocer como un tipo de explotación sexual comercial. Se trata de un abuso de poder donde las "esclavas" son tratadas como un objeto sexual, una mercancía. Ellas deben bailar sexy a cambio de una remuneración en metálico a terceras personas. Aunque a Rocío le sorprendió tal realidad, ni ella ni Berenice abandonaron la dramatización. Ellas continuaron desempeñando el rol de esclavas asignado por el Comité.

\section{Exhibición y subasta}

Rocío y Berenice comentan que fueron llevadas al gimnasio, a una especie de pasarela donde serían exhibidas y subastadas. Al respecto Rocío relata:

Ya llegando al gimnasio, ya ponen a las esclavas en la pasarela, a mí me tocó con otras dos chicas, nos vendieron a las tres juntas. Así lo eligieron los del Comité pero algunas las venden solas, depende de qué tan guapas estén, una era Gatubela y la otra no recuerdo. Nos dijeron que desfiláramos y ya después anuncian que alguien del público pase para que le bailáramos como de muestra, así sexy. Yo ni me movi tanto, te impone todas las personas que te ven, lo hice más o menos.

Rocío camina en una pasarela y baila de manera sexy. Aunque lo hace de mala gana, su actuación pública es de obediencia a las disposiciones del Comité. Rocío como Berenice experimentan el acoso, pero lo asumen como parte de la tradición. Al respecto, Berenice expone:

Después me dijeron te vamos a subastar. Me hicieron bailar en frente de todos, en el centro sentaron a dos chicos y bailamos las tres. Traté de sacar mis mejores pasos, pero no me gustó, habrá compañeras que si les guste pero en lo personal no. Estaba muy nerviosa. Con mucha pena esperando que alguien me comprara, porque ya me sentía así de trágame tierra. Jajaja... pues es como decir: "jchin, qué pena!, dejen de verme, escóndanme, jajaja..." Porque independientemente de que conozcas o 
no a la persona, es como decir cuánto das por mí, algo así como tipo prostitución, sólo que en juego. Es como un show, aplaudian, reían, me sentí como en una exhibición, la verdad fue penoso. Sí está divertido y todo el "coto"*, pero ya estando ahí, en frente de todos, es diferente. $Y$ que me compran, bueno junto con unas amigas éramos tres, empezaron desde quien da 5 pesos, y cuando la oferta iba en ciento y tantos que nos compran a las tres juntas jajaja... me acuerdo y me da risa.

Berenice experimenta los abusos de poder en medio del júbilo colectivo, pero esa realidad se le presenta de manera confusa, le parece "algo así como tipo prostitución, solo que en juego". Lo cual equivale a reconocer la explotación sexual, pero al mismo tiempo esa realidad es puesta en duda al considerarla un juego.

\section{El baile erótico}

Después de ser compradas las esclavas bailan eróticamente para su comprador. Este puede ser uno o varios amigos o el novio de la esclava. Al respecto Rocío comenta:

En la pasarela te empiezan a subastar, con nosotras empezaron con $\$ 50$ y de ahí subieron, pagaron $\$ 170$. Nos compró mi novio, con los del salón se cooperaron, le bailé a mi novio y las otras solo de lejecitos. Cuando estabas siendo subastada me sentía pues rara, como un objeto, aunque mi novio me compró y eso me dio tranquilidad. No le bailé muy elevado pues estábamos en frente de todos, no le bailé muy provocativo como de "reggaetón", me daba pena con las demás personas viendo.

Entre los compradores también hay policías, como en el caso de Berenice, quien tuvo que bailar para uno de ellos:

Pues en el momento pues dije ya me compraron, terminó esto, y como éramos varias, me sentí un poco mejor, todavía me acuerdo que un policía era el que estaba subiendo las subastas, elevaba las apuestas y compró a otra chica de otro grupo. Fuimos tres las subastadas, así que le tuvimos que bailar las tres a quien nos compró, pero en verdad es algo incómodo.

Aunque las informantes finalmente bailaron, no lo hicieron con sensualidad, atrevimiento o desenfreno. Parece que de forma intuitiva ellas deciden autocensurarse en el baile. Tal vez sea la prevalencia de un juicio moral sobre cómo debe comportarse una joven en público, pero también es una forma de hacer pública la incomodidad de estar siendo expuesta como una mercancía sexual y su desaprobación de ello.

Desde la perspectiva de los espectadores, la mayoría hombres, el baile erótico de las esclavas es un juego. Un joven estudiante espectador de la subasta y baile erótico comenta:

Pues algunas síbailan bien, pero otras son más serias, más tranquilas y a veces sí se ve que se sacan de onda cuando les piden que le bailen a alguien; yo digo que a las chavas las pueden llegar a manosear, pero hasta ahí. No creo que pase más. Es algo que forma parte de ese día, es un juego.

Otro joven espectador también habló del baile erótico como un juego, y encontró fantasioso juzgar la dramatiza-

\footnotetext{
* Cotorreo $=$ broma
}

ción como una explotación sexual, porque en realidad es juego:

Sí se ve medio feo la venta de esclavos. Depende de cada quién porque yo lo veo como un juego, pero pues no faltan los chavos fantasiosos que no son de aqui, las ven hasta como vagabundas o unas cualquiera. Bueno, echan a volar su imaginación.

Aunque parece que uno de los espectadores logra darse cuenta del "saque de onda" de las estudiantes esclavas y de que las pueden manosear, y de que el otro informante nota que "se ve medio feo la venta de esclavas"; ambos consideran que es un juego "inofensivo", no pasa del manoseo, es "algo que forma parte de ese día".

Terminada la celebración, continúa el baile de la noche. Ahí esclavas y esclavos dejan de serlo para convivir, bailar y beber alcohol con los amigos. Aunque el consumo de alcohol no se permite a los estudiantes durante la celebración y el baile, grupos de estudiantes burlan la vigilancia y durante el baile beben a discreción, varios hasta la embriaguez. Algunos terminan a golpes o accidentados. Un miembro del servicio de intendencia escolar dice que al otro día del baile, encontraron "un muchacho inconsciente sangrando por un botellazo, condones, orina por todos lados y hasta excremento".

Después de la celebración y el baile, Berenice comenta:

Después me agarraron de "coto", unos días horrible, fue el chisme de la semana. Además las chavas critican, ya sabrás cosas como que esta gorda, no bailó bien, y se ve mal; ya sabes... todas esas cosas que dices bueno equis, pero el chisme sí dura unos días. Sólo hacen comentarios y te señalan un rato, bajita la mano, pero con mis amigos para nada, sólo me dicen de repente, pero en broma.

Rocío y Berenice coinciden en señalar que con base en su experiencia, ellas no volverían a participar como esclavas. Al respecto, Berenice apunta:

Fue muy vergonzoso, sigo pensando eso, no lo volvería a hacer es como exhibirte y luego dicen cada cosa; todos se ríen, no se siente nada padre, la verdad a mí no me latió. O sea sí me avergoncé, pero no dije: "hay qué mal, me siento fatal" y cosas de esas, yo creo que fue sólo el momento, porque sólo queda como un recuerdo de diversión por parte de la escuela.

Por su parte, Rocío comenta:

De lo que realicé pienso que es parte de la tradición, pero no lo volvería a hacer. No me gustó bailar así, te sientes como un objeto que lo están vendiendo y que tienes que hacer un esfuerzo para que te compren, en este caso bailar muy bien. Al día siguiente, o a las semanas siguientes de hacerlo no me sentía mal, me decían las otras personas en la escuela ¿tú eras la chica maravilla no? Pero nada más, no cambió la forma en que se llevaban contigo, no hubo cruda moral por eso, pues es parte de la tradición de la escuela. Hasta ahorita no he tenido problemas con mi novio por eso, casi no lo recordamos.

\section{DISCUSIÓN}

La trata de personas con fines de explotación sexual se encuentra dispersa en las comunidades. Los resultados reportados indican que la trata puede aparecer como una representación pública y festejarse en la socialidad de una 
comunidad estudiantil, a pesar de incluir componentes reales de la violencia directa, estructural y simbólica que la caracterizan. Para tal efecto la violencia simbólica de la representación de la trata enmascara la realidad de la violencia directa y estructural, en el contexto de una celebración "desmadrosa". Una práctica cultural colectiva, divertida, lúdica, irreflexiva y autodestructiva. Similar a la sociabilidad del relajo, ${ }^{11}$ pero distinta por incluir diferentes tipos de violencia, incluida la explotación sexual y los excesos de alcohol, todo lo cual acentúa su carácter autodestructivo.

En este contexto las mujeres "esclavas" experimentan los efectos de la violencia como una realidad ambigua; dudan si lo que viven es explotación o juego. Después, su vergüenza, temor e incomodidad se vuelve algo secundario, irrelevante en términos de la celebración colectiva. Algunos hombres alcanzan a ver la vergüenza y el temor expresado por las estudiantes pero lo minimizan diciendo que es un juego, algo que forma parte de ese día.

En consecuencia los costos de participar en esta representación son diferentes para hombres y para mujeres, según su posición en esta organización social. Para las chicas que son esclavas genera mayor desgaste emocional, psicológico y social, incluso ya pasado el evento. Hay bromas, chismes, comentarios incisivos sobre su "papel como esclavas" en lo físico, la vestimenta y sobre su reputación. No resulta así, ni se cuestiona lo que hace la mayoría de los hombres estudiantes que participan como captores, compradores, subastadores u organizadores, incluidas las autoridades y directivos que apoyan la celebración estudiantil.

Desde un enfoque sociocultural, la representación de la trata es una práctica machista de los estudiantes, donde desempeñan el papel de jóvenes "desmadrosos"15 y "calientes", ${ }^{14}$ festejando a la mujer de sus deseos: dócil y dulce, y al mismo tiempo atrevida y fácil; una mercancía sexual, algo que se puede comprar y luego desechar sin compromiso. Por lo tanto lo que juzgan los estudiantes es el ajuste de la joven a la imagen de objeto sexual. De esta forma se evalúa si el físico o la vestimenta de las jóvenes, sumado a su baile erótico, contribuye o no al imaginario e ideal de la mujer "femenina" deseada en el desmadre.

Cuando muchachas como Brenda se tiran un clavado, luchan en el lodo o se disfrazan de conejitas de "play boy" o bailan eróticamente al mejor postor, están representando públicamente su adhesión a los deseos y las prácticas machistas. Quizá lo que dice Brenda es mentira, su dicho puede ser una mera táctica en situaciones de presión social. Incluso puede ser el medio de dar a saber públicamente la incomodidad y su desaprobación de la participación obligada en ese momento. En cualquier caso lo que basta es que ella bailó públicamente, expresando así una apariencia de unanimidad y de consentimiento con los deseos y prácticas machistas. De acuerdo con Bourdieu ${ }^{8}$ se puede suponer que esta especie de complicidad de las víctimas no es ni sumisión pasiva ni adhesión libre a los valores machistas. Las emociones experimentadas por las estudiantes esclavizadas, entre ellas la vergüenza, los "nervios", el "miedito", la rareza o el "sentirse así de trágame tierra", revelan que la obediencia, la sumisión o la adhesión que se otorga a la visión dominante no pasa por el consentimiento reflexionado sino que se otorga a pesar de uno mismo.

En estas circunstancias se desarrolla un doble discurso: por un lado, el público, el de la mayoría masculina, lleno de eufemismos, de referencias a una alegría desbordada y de unanimidad con los deseos y las prácticas machistas. Por otro lado está el discurso oculto ${ }^{16}$ de las mujeres esclavizadas, el cual habla de vergüenza y temor. De acuerdo con Scoot, ${ }^{16}$ a partir de este sufrimiento y en secreto, los grupos subordinados desarrollan un "discurso oculto" que representa una resistencia al poder, como el de Rocío y Berenice, quienes tienen su propia historia y su propia experiencia acumulada con las desigualdades de género, lo cual les permite anticipar en su discurso su rechazo a volver a participar como esclavas.

A partir de los resultados obtenidos se puede suponer que existe un discurso oculto de las víctimas de trata de personas a cargo del crimen organizado, que puede esconder sus prácticas y encubrir sus voces rebeldes, pero también los problemas de salud mental padecidos a causa de las violencias directa y estructural de la trata. Con ello se corre el riesgo de agravar esos problemas, pues están alejados de la investigación y de los servicios de salud mental. Quizás esta lejanía y ocultamiento propiciado por la trata también puede explicar, por lo menos parcialmente, el escaso número de investigaciones sobre las consecuencias psicológicas y sociales de la trata y de programas para su atención basados en la evidencia. ${ }^{2,17,18}$

\section{REFERENCIAS}

1. Casillas R. La trata de mujeres, adolescentes, niñas y niños en México. Un estudio exploratorio en Tapachula, Chiapas. México: Comisión Interamericana de Mujeres, Organización de Estados Americanos, Organización Internacional para las Migraciones, Instituto Nacional de las Mujeres, Instituto Nacional de Migración; 2006.

2. Le Goff $\mathbf{H}$, Lothar T. La trata de personas en México. Diagnóstico sobre la asistencia a víctimas. Organización Internacional para las Migraciones Misión México; 2011.

3. Rodríguez E, Gutiérrez R, Vega L. Consumo de drogas en mujeres dedicadas a la prostitución: la zona de La Merced. Salud Mental 2003;26(5):73-81.

4. Oram $S$ et al. Prevalence and risk of violence and the physical, mental, and sexual health problems associated with human trafficking: systematic review. PLoS Medicine 2012;9(5):e1001224.

5. Hossain $\mathrm{M}$ et al. The relationship of trauma to mental disorders among trafficked and sexually exploited girls and women. American Journal of Public Health 2010;100(12):2442-2449.

6. Rodriguez E, Fuentes $P$ (Compiladoras). Visibilizando las necesidades de salud mental de las trabajadoras sexuales. México: INPRF y SSA; 2013.

7. Gutiérrez R, Vega L, Rendon E. Riesgos de explotación sexual de adolescentes usuarios de las nuevas tecnologías. En Una Mirada a la infancia y la adolescencia en México. $4^{\text {a }}$ Premio UNICEF. México: UNICEF; 2013. 
8. Bourdieu P. La dominación masculina, Barcelona: Anagrama; 2005.

9. Maffesoli, M., El tiempo de las tribus. El ocaso del individualismo en las sociedades posmodernas, México, Siglo XXI. 2004.

10. Simmel G. Sobre la individualidad y las formas sociales. Escritos escogidos, Buenos Aires, Universidad Nacional de Quilmes. 2002. [1917].

11. Portilla Fenomenología del relajo. México: FCE 1966.

12. Hernández González J. Construir una identidad. Vida juvenil y estudio en cch sur. Revista Mexicana Investigación Educativa 2006;11(29):459-481.

13. WEISS, Eduardo Los estudiantes como jóvenes. El proceso de subjetivación. Perfiles Educativos 2012;34(135):134-148.

14. Gutmann M. "La "falocedad" de continuos: salud reproductiva entre los adolescentes de Oaxaca de Juárez." Estudios Sociales 2005;13 (26): 118-143.
15. Magazine R. Azul y oro como mi corazón. Masculinidad y poder en una porra de los Pumas de la UNAM. México Universidad Iberoamericana. 2008.

16. Scott J. Domination and the Arts of Resistance. Hidden Transcript. Michigan Yale University: New Haven and London; 1990.

17. Ostrovschi $\mathbf{N}$ et al. Women in post-trafficking services in Moldova: diagnostic interviews to assess common mental disorders over two time periods among returning women. Bio Med Central Public Health 2011;11:232.

18. Schinina G. Psychosocial support to groups of victims of human trafficking in transit situations. Ginebra, Organización Internacional para las Migraciones, 2004.

Artículo sin conflicto de intereses 